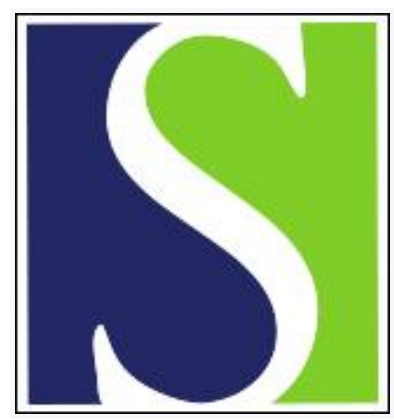

Scand J Work Environ Health 2014;40(4):420-427

https://doi.org/10.5271/sjweh.3434

Published online: 08 May 2014, Issue date: 01 Jul 2014

Occupational asbestos exposure and risk of oral cavity and pharyngeal cancer in the prospective Netherlands Cohort Study

by Offermans NSM, Vermeulen R, Burdorf A, Goldbohm RA, Keszei AP, Peters S, Kauppinen $T$, Kromhout $H$, van den Brandt PA

Within a population-based study, we estimate the association between occupational asbestos exposure and risk of oral cavity and pharyngeal cancer. There was no convincing evidence of an association between asbestos and risk of both cancers, as an exposure-response relation was lacking. However, the potentially increased hazard ratios of pharyngeal cancer observed in this and previous studies warrant further research.

Affiliation: Department of Epidemiology, Maastricht University Medical Centre, P.O. Box 616, 6200 MD Maastricht, The Netherlands. pa.vandenbrandt@maastrichtuniversity.nl

Refers to the following text of the Journal: 2006;32(4):270-275

Key terms: asbestos; asbestos exposure; cohort study; confounder; confounding; exposure-response; interaction; JEM; job-exposure matrix; occupational exposure; oral cavity; oral cavity cancer; pharyngeal cancer; population-based study; The Netherlands

This article in PubMed: www.ncbi.nlm.nih.gov/pubmed/24810833 


\title{
Occupational asbestos exposure and risk of oral cavity and pharyngeal cancer in the prospective Netherlands Cohort Study
}

\author{
by Nadine SM Offermans, MSc, ${ }^{1}$ Roel Vermeulen, PhD, ${ }^{2,3}$ Alex Burdorf, PhD, ${ }^{4}$ R Alexandra Goldbohm, \\ PhD, ${ }^{5}$ András P Keszei, PhD, ${ }^{1}$ Susan Peters, PhD, ${ }^{2,6}$ Timo Kauppinen, PhD, ${ }^{7}$ Hans Kromhout, PhD, ${ }^{2}$ Piet \\ $A$ van den Brandt, $P h D^{1}$
}

Offermans NSM, Vermeulen R, Burdorf A, Goldbohm RA, Keszei AP, Peters S, Kauppinen T, Kromhout H, van den Brandt PA. Occupational asbestos exposure and risk of oral cavity and pharyngeal cancer in the prospective Netherlands Cohort Study. Scand J Work Environ Health. 2014;40(4):420-427. doi:10.5271/sjweh.3434

\begin{abstract}
Objectives The evidence for an association between occupational asbestos exposure and pharyngeal cancer $(\mathrm{PhC})$ is limited, while for oral cavity cancer (OCC) the literature is even sparser. We studied OCC and $\mathrm{PhC}$ risk both separately and combined (OCPC) in relation to occupational asbestos exposure, specifically addressing the influence of potential confounders, the existence of an exposure-response relation, and the presence of interaction between asbestos and smoking.
\end{abstract}

Methods Using the prospective Netherlands Cohort Study (N=58 279 men, aged 55-69 years), we estimated asbestos exposure by linkage to a general population job-exposure matrix (DOMJEM) and a Finnish job-exposure matrix (FINJEM). After 17.3 years of follow-up, 58 OCC and $53 \mathrm{PhC}$ cases were available for analysis.

Results No association between asbestos and risk of OCC was observed for either JEM. Hazard ratios (HR) of $\mathrm{PhC}$ and OCPC increased after adjusting for confounders, particularly alcohol consumption and socioeconomic status. For PhC, a multivariable-adjusted increased HR was observed for "ever" versus "never" exposed to asbestos [HR 2.20, 95\% confidence interval (95\% CI) 1.08-4.49] when using FINJEM, but a trend of increased risks with higher cumulative exposure could not be demonstrated for either JEM. Results for OCPC showed patterns similar to those observed for PhC. None of the cancers showed a significant interaction between asbestos and smoking.

Conclusions This prospective population-based study showed no convincing evidence of an association between asbestos and risk of $\mathrm{OCC}, \mathrm{PhC}$, and OCPC as an exposure-response relation was lacking, and results were not robust against the use of different JEM. However, the potentially increased HR of PhC and OCPC observed in this and previous studies warrant further research.

Key terms confounder; confounding; exposure-response; interaction; JEM; job-exposure matrix; populationbased study.

Together, oral cavity cancer (OCC) and pharyngeal cancer $(\mathrm{PhC})$ are the eighth most frequently occurring neoplasms worldwide, giving rise to 482000 new cases in 2008 (1). The main risk factors for OCC and $\mathrm{PhC}$ are (excessive) alcohol consumption and all forms of tobacco use, while fruits and vegetables have been associated with a decreased risk (2). Occupational carcinogens, such as polycyclic aromatic hydrocarbons (3) and solvents (4), may also be involved in the etiology of both cancers, but the strongest suggestion of a possible association focuses on asbestos exposure $(3,5,6)$. There are, however, no supportive data from animal studies and a clear exposureresponse relation for asbestos exposure is lacking (5). As such, there is still debate whether asbestos exposure increases the risk of developing $\mathrm{OCC}$ and $\mathrm{PhC}$, and if so, whether risk increases with increasing level of cumulative

1 Department of Epidemiology, GROW School for Oncology \& Developmental Biology, Maastricht University MC, Maastricht, The Netherlands.

2 Institute for Risk Assessment Sciences, Environmental Epidemiology Division, Utrecht University, Utrecht, The Netherlands.

3 Julius Center for Health Sciences and Primary Care, University Medical Center, Utrecht, The Netherlands.

4 Department of Public Health, Erasmus MC, Rotterdam, The Netherlands.

5 TNO, Leiden, The Netherlands.

6 Epidemiology Group, Centre for Medical Research, University of Western Australia, Perth, WA, Australia.

7 Finnish Institute of Occupational Health, Helsinki, Finland.

Correspondence to: Piet A van den Brandt, Department of Epidemiology, Maastricht University Medical Centre, P.O. Box 616, 6200 MD Maastricht, The Netherlands. [E-mail: pa.vandenbrandt@maastrichtuniversity.nl] 
exposure. Besides questions on the strength of a possible association, there are additional questions relating to (i) the association with OCC and PhC separately, as they have often been combined in previous research; (ii) possible confounding by other risk factors, such as smoking and alcohol consumption, as most previous studies were performed in an industry-setting and were unable to adjust for these factors; and (iii) the presence of an interaction between exposure to asbestos and smoking in relation to the risk of OCC and $\mathrm{PhC}$, as has been suggested for other asbestos-related cancers $(5,6)$.

Population-based studies are well-suited to address these questions given their overall wide range in exposure levels, possibility to control for potential confounders, and large size. The prospective Netherlands Cohort Study (NLCS) is a population-based study, which started in 1986 among 120852 men and women of the general population (7). Within the framework of the current investigation, we had the following objectives: (i) to investigate the association between occupational asbestos exposure and risk of OCC and $\mathrm{PhC}$ both separately and combined, paying special attention to the existence of an exposure-response relation and the influence of potential confounding on risk estimates; (ii) to study the presence of an interaction between asbestos and smoking in relation to the risk of OCC and $\mathrm{PhC}$, both separately and combined.

As the proportion of long-term employed women was rather low (resulting in $<1 \%$ being occupationally exposed to asbestos), this study was conducted only among men.

\section{Methods}

\section{Study population and cancer follow-up}

The study design and data collection strategies for the NLCS have been described in detail previously (7). In brief, the NLCS started in September 1986 when 58279 men and 62573 women aged 55-69 years, originating from 204 municipalities in the Netherlands with computerized population registries, were enrolled in the cohort (response rate $35.5 \% ; 34.5 \%$ among men and $36.6 \%$ among women). At baseline, participants completed a self-administered questionnaire on dietary habits and lifestyle, occupational history, and other potential risk factors for cancer (7). For reasons of efficiency in questionnaire processing and follow-up, the case-cohort approach was used (8). Incident cases were enumerated from the entire cohort, whereas the accumulated person-years at risk in the entire cohort were estimated from a random subcohort of 5000 subjects $(2411$ men and 2589 women), selected immediately after baseline.
This subcohort is being followed-up for vital status information while the entire cohort is being monitored for incident cancer by annual record linkage to the Netherlands Cancer Registry and the Dutch Pathology Registry (PALGA) $(9,10)$. For current analyses, a total of 17.3 years of follow-up (baseline to December 2003) was available. Completeness of incident cancer coverage was estimated to be almost $100 \%$ (11) as was the completeness of follow-up of the subcohort. The institutional review boards of the Netherlands Organization for Applied Scientific Research TNO (Zeist) and Maastricht University approved the NLCS.

End points for this study were incident, microscopically confirmed OCC and $\mathrm{PhC}$ cases classified by anatomic site or histological type, as defined by the International Classification of Diseases for Oncology, Third Edition. Tumor assignment followed the International Head and Neck Cancer Epidemiology Consortium (INHANCE) collaboration classification (12) and consisted of the following categories: (i) oral cavity (includes lip, tongue, gum, floor of mouth, and hard palate): codes $\mathrm{C} 00.3$ C00.9, C02.0-C02.3, C03.0, C03.1, C03.9, C04.0, C04.1, C04.8, C04.9, C05.0, C06.0-C06.2, C06.8, and C06.9; (ii) pharynx, consisting of (a) oropharynx (includes base of tongue, lingual tonsil, soft palate, uvula, tonsil, and oropharynx): codes C01.9, C02.4, C05.1, C05.2, C09.0, C09.1, C09.8, C09.9, C10.0-C10.4, C10.8, and C10.9; and (b) hypopharynx (includes pyriform sinus and hypopharynx): codes C12.9, C13.0-C13.2, C13.8, and C13.9; 3 ) oral cavity, pharynx unspecified or overlapping: codes C02.8, C02.9, C05.8, C05.9, C14.0, C14.2, and C14.8. As most tumors in our study originated from squamous cell tissue (89.6\%), analyses were restricted to cases with squamous cell carcinomas.

Other than skin cancer, all prevalent cases at baseline were excluded, leaving 2336 male subcohort members, $71 \mathrm{OCC}$ and $74 \mathrm{PhC}$ cases (50 oropharynx and 24 hypopharynx). Cases that could not be classified as oropharynx, hypopharynx, or oral cavity $(\mathrm{N}=2)$ were included only when analyzing $\mathrm{OCC}$ and $\mathrm{PhC}$ together (OCPC; $\mathrm{N}=147$ ). Due to the low number of oro- and hypopharyngeal cancer cases, no subtype analyses were performed. Subjects without any, or only uncodable, information on occupational history or who never worked professionally were omitted from the analyses. As a result, 2101 male subcohort members, $63 \mathrm{OCC}, 67 \mathrm{PhC}$, and 132 OCPC cases were available for analysis after 17.3 years of follow-up.

\section{Occupational exposure assessment}

Information on lifetime occupational history until 1986 was obtained from the questionnaire completed on study enrolment. Questions concerned the job title, name and type of the company, products made in the department, 
and period of employment. For all subjects, the job code was assessed for each of the maximally five occupations subjects could enter between starting work and 1986.

Job-exposure matrix. We applied two job-exposure matrices (JEM), a general population JEM from the Netherlands (DOMJEM) and a Finnish JEM (FINJEM) as described previously (13), in order to provide insight into the methodological uncertainty associated with choice of JEM with respect to asbestos exposure. DOMJEM and FINJEM showed moderate agreement amongst each other and rather similar agreement with case-bycase expert assessment. Briefly, occupational exposure experts in the Netherlands developed DOMJEM for application in general population studies. It contains a combined measure of the probability $\times$ intensity of exposure, which is ordinal (no, low, or high exposure) with a weighting of respectively 0,1 , or 4 (14). FINJEM was constructed for exposure assessment in large registerbased studies and is based on both expert assessment and exposure measurements. It contains continuous estimates of the prevalence and intensity of exposure both separately and combined, and contains a time axis (15). Although FINJEM was constructed for Finland, exposure estimates were not adapted to Dutch occupational circumstances before application in the NLCS.

Asbestos exposure variables. Several exposure variables were defined, which we have described in more detail elsewhere: ever versus never occupationally exposed to asbestos (yes/no), cumulative exposure [CE; a combined measure of the probability (P), intensity (I), and duration (years) of exposure, measured in fiber-years/ml (f-y/ $\mathrm{ml}$ ) (FINJEM) or unit-years (DOMJEM)], ever versus never highly exposed to asbestos (yes/no), and duration of high exposure (years) (16).

Participants were classified into never-exposed subjects and tertiles of those exposed to asbestos based on the distribution among the subcohort for the $\mathrm{CE}$ (never exposed=reference group) and for the duration of high exposure (never highly exposed=reference group). Continuous variables were also used; for the $\mathrm{CE}$, an increment of 1 unit-year (DOMJEM) or $1 \mathrm{f}-\mathrm{y} / \mathrm{ml}$ (FINJEM) was used.

For the percentage of the population for whom some information on occupational history could not be coded, exposure to asbestos was set to zero for the period with unclear exposure.

\section{Statistical analysis}

Cox proportional hazards models were used to estimate age-adjusted as well as multivariable-adjusted hazard ratios (HR) and corresponding 95\% confidence intervals (95\% CI).
The total person-years at risk were estimated from the subcohort (17), and we estimated standard errors using a robust covariance matrix estimator to account for increased variance due to sampling the subcohort from the entire cohort (18).

The covariates included in the multivariable-adjusted models were either a priori-selected risk factors based on the literature or variables that changed the age-adjusted regression coefficients by $\geq 10 \%$ (using a backwards stepwise procedure). Smokeless tobacco has not been included in the multivariable-adjusted model as the total number of cases that used this form of tobacco was too low $(\mathrm{N}=4)$ to be of any influence as a confounder in the NLCS. Polycyclic aromatic hydrocarbons and solvents have also not been included in the final model as these exposures hardly changed the age-adjusted regression coefficients. For all endpoints, the full covariate model consisted of smoking status (never/former/current), number of cigarettes smoked per day (centered variable), years of smoking cigarettes (centered variable), socioeconomic status (by level of education; lower vocational, secondary and medium vocational, and higher vocational/university), alcohol consumption, and consumption of vegetables. Information on consumption of vegetables was gathered in the dietary section of the baseline questionnaire. This section consisted of a 150item semi-quantitative food-frequency questionnaire, which concentrated on habitual consumption during the year preceding the start of the study.

All covariates were entered into the models as continuous variables, except for smoking status and socioeconomic status. To enable comparison, the models adjusted for age and family history of cancer were restricted to subjects included in the multivariableadjusted analyses (ie, with no missing values on confounding variables), which left 1858 subcohort members, 58 OCC, $53 \mathrm{PhC}$, and 113 OCPC cases for analyses. For each analysis, scaled Schoenfeld residuals were used to test the proportional hazards assumption (19). Trends for all subjects were evaluated with the Wald test by assigning subjects the median value for each level of the categorical variable among the subcohort members, and this variable was entered as a continuous term in the Cox regression model.

Furthermore, we tested for a possible interaction between occupational exposure to asbestos (yes/no) and smoking status (never/former/current) in relation to OCC, $\mathrm{PhC}$, and OCPC. As testing for departure from additivity was not possible due to low numbers, we only studied statistically significant departure from multiplicativity by including an interaction term in the Cox regression model. All tests (2-tailed) were performed using Stata, version 10 (Stata Corp, College Station, TX, USA), and differences were regarded as statistically significant at $\mathrm{P}<0.05$. 


\section{Results}

The distribution of occupational exposure to asbestos and potential confounders among male subcohort members and cancer cases in the NLCS is presented in table 1. Overall, OCC and $\mathrm{PhC}$ cases more often smoked cigarettes, smoked more cigarettes per day and for a longer period of time, and consumed more alcohol per day than subcohort members. OCC and $\mathrm{PhC}$ cases generally had a higher socioeconomic status than subcohort members. According to both JEM, OCC cases were overall less often exposed to asbestos than subcohort members, while PhC cases were more often exposed. As the number of highly exposed subjects was very low, certainly for DOMJEM, no further results will be presented for ever versus never highly exposed and the duration of high exposure.

Overall, most asbestos exposure variables showed no association with OCC, PhC, and OCPC (table 2). Adjusting for potential confounders was generally of minor influence, except for alcohol consumption and socioeconomic status, which increased the $\mathrm{HR}$ of $\mathrm{PhC}$ and OCPC. Therefore, only multivariable-adjusted results are presented below.

For OCC, no associations were observed when using

Table 1. Distribution of potential confounders and asbestos exposure a among male subcohort members and cancer cases in the Netherlands Cohort Study (NLCS) 1986-2003. [SD=standard deviation; DOMJEM=Dutch general population job-exposure matrix; FINJEM=Finnish JEM; M=median]

\begin{tabular}{|c|c|c|c|c|c|c|c|c|c|c|c|c|}
\hline & \multicolumn{4}{|c|}{ Subcohort $(\mathrm{N}=2101)$} & \multicolumn{4}{|c|}{ Oral cavity cancer cases $(\mathrm{N}=63)$} & \multicolumn{4}{|c|}{ Pharyngeal cancer cases $(\mathrm{N}=67)$} \\
\hline & $\mathrm{N}$ & $\%$ & Mean & SD & $\mathrm{N}$ & $\%$ & Mean & SD & $\mathrm{N}$ & $\%$ & Mean & SD \\
\hline Age at baseline (years) & 2101 & . & 61.3 & 4.2 & 63 & . & 61.7 & 4.2 & 67 & . & 62.1 & 4.2 \\
\hline \multicolumn{13}{|l|}{ Cigarette smoking } \\
\hline Never & 263 & 12.5 & . & . & 11 & 17.5 & . & . & 3 & 4.5 & . & . \\
\hline Former & 1079 & 51.4 & . & . & 14 & 22.2 & . & . & 22 & 32.8 & . & . \\
\hline Current & 759 & 36.1 & . & . & 38 & 60.3 & . & . & 42 & 62.7 & . & . \\
\hline Number of cigarettes per day b,c & 1717 & . & 17.1 & 10.6 & 47 & . & 21.2 & 11.5 & 55 & . & 22.6 & 13.4 \\
\hline Years of smoking b, c (years) & 1802 & . & 33.6 & 11.9 & 50 & . & 39.5 & 9.0 & 61 & . & 39.8 & 9.8 \\
\hline \multicolumn{13}{|l|}{ Level of education } \\
\hline Lower vocational & 973 & 46.3 & . & . & 20 & 31.7 & . & . & 30 & 44.8 & . & . \\
\hline Secondary and medium vocational & 733 & 34.9 & . & . & 26 & 41.3 & . & . & 17 & 25.4 & . & . \\
\hline Higher vocational/university & 395 & 18.8 & . & . & 17 & 27.0 & . & . & 20 & 29.8 & . & . \\
\hline Alcohol consumption ${ }^{c}(\mathrm{~g} / \mathrm{d})$ & 2060 & . & 15.1 & 16.9 & 62 & . & 33.3 & 27.7 & 65 & . & 38.4 & 32.7 \\
\hline Consumption of vegetables $(\mathrm{g} / \mathrm{d})$ & 2101 & . & 191.2 & 86.4 & 63 & . & 189.3 & 77.8 & 67 & . & 181.5 & 86.4 \\
\hline \multicolumn{13}{|l|}{ DOMJEM } \\
\hline Never exposed d & 1496 & 71.2 & . & . & 50 & 79.4 & . & . & 47 & 70.2 & . & . \\
\hline Ever exposed ${ }^{d}$ & 605 & 28.8 & . & . & 13 & 20.6 & . & . & 20 & 29.8 & . & . \\
\hline \multicolumn{13}{|c|}{$\begin{array}{l}\text { Cumulative probabilityxintensity of exposure } \\
\text { (unit-years) }\end{array}$} \\
\hline $\mathrm{T} 1(\mathrm{M}=4)$ & 215 & 35.5 & . & . & 5 & 38.5 & . & . & 5 & 25.0 & . & . \\
\hline $\mathrm{T} 2(\mathrm{M}=20)$ & 191 & 31.6 & . & . & 7 & 53.8 & . & . & 9 & 45.0 & . & . \\
\hline T3 (M=38) & 199 & 32.9 & . & . & 1 & 7.7 & . & . & 6 & 30.0 & . & . \\
\hline Ever highly exposed e & 49 & 2.3 & . & . & 0 & 0.0 & . & . & 1 & 1.5 & . & . \\
\hline \multicolumn{13}{|l|}{ Duration of high exposure e (years) } \\
\hline $\mathrm{T} 1(\mathrm{M}=4)$ & 17 & 34.6 & . & . & 0 & 0.0 & . & . & 0 & 0.0 & . & . \\
\hline $\mathrm{T} 2(\mathrm{M}=10.5)$ & 16 & 32.7 & . & . & 0 & 0.0 & . & . & 0 & 0.0 & . & . \\
\hline T3 $(\mathrm{M}=30.5)$ & 16 & 32.7 & . & . & 0 & 0.0 & . & . & 1 & 100.0 & . & . \\
\hline \multicolumn{13}{|l|}{ FINJEM } \\
\hline Never exposed d & 1559 & 74.2 & . & . & 49 & 77.8 & . & . & 47 & 70.2 & . & . \\
\hline Ever exposed ${ }^{d}$ & 542 & 25.8 & . & . & 14 & 22.2 & . & . & 20 & 29.8 & . & . \\
\hline \multicolumn{13}{|c|}{$\begin{array}{l}\text { Cumulative probabilityxintensity of exposure } \\
(\mathrm{f}-\mathrm{y} / \mathrm{ml})\end{array}$} \\
\hline $\mathrm{T} 1(\mathrm{M}=0.20)$ & 181 & 33.4 & . & . & 5 & 35.7 & . & . & 9 & 45.0 & . & . \\
\hline $\mathrm{T} 2(\mathrm{M}=1.59)$ & 180 & 33.2 & . & . & 5 & 35.7 & . & . & 8 & 40.0 & . & . \\
\hline T3 (M=6.60) & 181 & 33.4 & . & . & 4 & 28.6 & . & . & 3 & 15.0 & . & . \\
\hline Ever highly exposed e & 290 & 13.8 & . & . & 7 & 11.1 & . & . & 6 & 9.0 & . & . \\
\hline \multicolumn{13}{|l|}{ Duration of high exposure e (years) } \\
\hline $\mathrm{T} 1(\mathrm{M}=6)$ & 100 & 34.4 & . & . & 1 & 14.3 & . & . & 2 & 33.3 & . & . \\
\hline T2 (M=20) & 95 & 32.8 & . & . & 5 & 71.4 & . & . & 3 & 50.0 & . & . \\
\hline T3 (M=35) & 95 & 32.8 & . & . & 1 & 14.3 & . & . & 1 & 16.7 & . & . \\
\hline
\end{tabular}

a Exposure dichotomized or categorized in never-exposed and tertiles (T) of exposed in the subcohort.

${ }^{\mathrm{b}}$ Among former and current smokers only.

c Sum of categories deviates from total number because of missing values.

${ }^{d}$ Exposure based on the cumulative probability ${ }^{\star}$ intensity of exposure (unit-years or $\mathrm{f}-\mathrm{y} / \mathrm{ml}$ ).

${ }^{\text {e }}$ Exposure based on the probability*intensity of exposure (unit-years or $\mathrm{f}-\mathrm{y} / \mathrm{ml}$ ) per job. 
Table 2. Hazard ratios (HR) and $95 \%$ confidence intervals $(95 \% \mathrm{Cl}$ ) for oral cavity and pharyngeal cancer both separately and combined, for categories of asbestos exposure a estimated with a general population and Finnish job-exposure matrix (DOMJEM and FINJEM) in the Netherlands Cohort Study (NLCS), 1986-2003. [M=median]

\begin{tabular}{|c|c|c|c|c|c|c|c|c|c|c|c|c|c|c|c|c|}
\hline & \multirow{2}{*}{$\begin{array}{c}\text { Person- } \\
\text { years } \\
\text { in sub- } \\
\text { cohort }\end{array}$} & \multicolumn{5}{|c|}{ Oral cavity cancer } & \multicolumn{5}{|c|}{ Pharyngeal cancer } & \multicolumn{5}{|c|}{$\begin{array}{c}\text { Oral cavity and pharyngeal cancer } \\
\text { combined }\end{array}$} \\
\hline & & $\mathrm{N}$ & $\mathrm{HR}^{\mathrm{b}, \mathrm{c}}$ & $95 \% \mathrm{Cl}$ & $\mathrm{HR}^{\mathrm{d}, \mathrm{e}}$ & $95 \% \mathrm{Cl}$ & $\mathrm{N}$ & $\mathrm{HR}^{\mathrm{b}, f}$ & $95 \% \mathrm{Cl}$ & $\mathrm{HR}^{\mathrm{d}, \mathrm{g}}$ & $95 \% \mathrm{Cl}$ & $N$ & $\mathrm{HR}^{\mathrm{b}, \mathrm{h}}$ & $95 \% \mathrm{Cl}$ & $H R d, i$ & $95 \% \mathrm{Cl}$ \\
\hline \multicolumn{17}{|l|}{ DOMJEM } \\
\hline Never exposed i & 19246 & 46 & 1 & .. & 1 & .. & 37 & 1 & .. & 1 & .. & 85 & 1 & .. & 1 & .. \\
\hline $\begin{array}{l}\text { Ever exposed } \\
\text { Cumulative } \\
\text { probabilityxinten } \\
\text { of exposure } \\
\text { (unit-years) }\end{array}$ & $\begin{array}{l}7421 \\
\text { nsity }\end{array}$ & 12 & 0.70 & $0.37-1.34$ & 0.86 & $0.41-1.82$ & 16 & 1.15 & $0.63-2.10$ & 1.16 & $0.56-2.38$ & 28 & 0.88 & $0.57-1.37$ & 0.99 & $0.58-1.69$ \\
\hline $\mathrm{T} 1(\mathrm{M}=4)$ & 2891 & 5 & 0.74 & $0.29-1.89$ & 0.72 & $0.22-2.32$ & 4 & 0.73 & $0.26-2.08$ & 0.44 & $0.10-1.86$ & 9 & 0.72 & $0.35-1.46$ & 0.57 & $0.22-1.51$ \\
\hline $\mathrm{T} 2(\mathrm{M}=20)$ & 1997 & 6 & 1.31 & $0.55-3.16$ & 2.17 & $0.83-5.70$ & 8 & 2.17 & $0.98-4.81$ & 3.18 & $1.24-8.15$ & 14 & 41.66 & $0.91-3.02$ & 2.56 & $1.28-5.09$ \\
\hline T3 (M=38) & 2533 & 1 & 0.17 & $0.02-1.26$ & 0.24 & $0.03-1.78$ & 4 & 0.85 & $0.30-2.41$ & 1.09 & $0.37-3.20$ & 5 & 0.46 & $0.19-1.16$ & 0.62 & $0.24-1.58$ \\
\hline $\begin{array}{l}\text { Continuous } \\
\text { (per } 1 \text { unit-year }\end{array}$ & 26667 & 58 & 0.98 & $0.95-1.00$ & 0.98 & $0.96-1.01$ & 53 & 1.01 & $0.99-1.02$ & 1.01 & $0.99-1.03$ & 113 & 1.00 & $0.98-1.01$ & 1.00 & $0.99-1.02$ \\
\hline
\end{tabular}

FINJEM

\begin{tabular}{|c|c|c|c|c|c|c|c|c|c|c|c|c|c|c|c|c|}
\hline \multirow{3}{*}{\multicolumn{2}{|c|}{$\begin{array}{l}\text { Never exposed i } 20204 \\
\text { Ever exposed i } 6463 \\
\text { Cumulative } \\
\text { probabilityxintensity } \\
\text { of exposure } \\
\text { (f-y/ml) }\end{array}$}} & 47 & 1 & .. & 1 & .. & 36 & 1 & .. & 1 & .. & 85 & 1 & .. & 1 & .. \\
\hline & & 11 & 0.76 & $0.39-1.50$ & 1.18 & $0.53-2.61$ & 17 & 1.54 & $0.86-2.75$ & 2.20 & $1.08-4.49$ & 28 & 1.07 & $0.69-1.67$ & 1.59 & $0.93-2.73$ \\
\hline & & & & & & & & & & & & & & & & \\
\hline $\mathrm{T} 1(\mathrm{M}=0.20)$ & 2215 & 5 & 1.00 & $0.39-2.57$ & 1.71 & $0.61-4.82$ & 9 & 2.35 & $1.11-4.96$ & 4.04 & $1.69-9.64$ & 14 & 1.55 & $0.86-2.80$ & 2.64 & $1.34-5.19$ \\
\hline T2 (M=1.59) & 2187 & 4 & 0.85 & $0.30-2.38$ & 1.51 & $0.49-4.65$ & 7 & 1.92 & $0.84-4.39$ & 3.01 & $1.14-7.96$ & 11 & 1.28 & $0.67-2.46$ & 2.15 & $1.02-4.52$ \\
\hline T3 (M=6.60) & 2061 & 2 & 0.43 & $0.10-1.79$ & 0.54 & $0.12-2.47$ & 1 & 0.28 & $0.04-2.05$ & 0.30 & $0.04-2.46$ & 3 & 0.36 & $0.11-1.14$ & 0.42 & $0.12-1.50$ \\
\hline $\begin{array}{l}\text { Continuous } \\
\text { (per } 1 \text { fiber-year }\end{array}$ & $\begin{array}{l}26667 \\
\text { r) }\end{array}$ & 58 & 0.87 & $0.73-1.03$ & 0.90 & $0.79-1.03$ & 53 & 0.84 & $0.69-1.02$ & 0.84 & $0.71-0.98$ & 113 & 0.85 & $0.75-0.97$ & 0.87 & $0.78-0.97$ \\
\hline
\end{tabular}

a Exposure dichotomized or categorized in never-exposed and tertiles (T) of exposed in the subcohort.

${ }^{\mathrm{b}}$ Age-adjusted model.

c P-value for trend: DOMJEM=0.133; FINJEM=0.257.

${ }^{\mathrm{d}}$ Adjusted for age (years), smoking status (never/former/current), number of cigarettes smoked per day (centered variable), years of smoking cigarettes (centered variable), level of education (three categories), alcohol consumption ( $\mathrm{g} /$ day), and consumption of vegetables ( $\mathrm{g} / \mathrm{day})$.

e $\mathrm{P}$-value for trend: DOMJEM=0.415; FINJEM=0.753.

f $\mathrm{P}$-value for trend: DOMJEM=0.578; FINJEM=0.816.

g P-value for trend: DOMJEM=0.289; FINJEM=0.360.

h P-value for trend: DOMJEM=0.450; FINJEM=0.412.

i $P$-value for trend: DOMJEM=0.918; FINJEM=0.740.

${ }^{\lrcorner}$Exposure based on the cumulative probability*intensity of exposure (unit-years or $\mathrm{f}-\mathrm{y} / \mathrm{ml}$ ).

DOMJEM or FINJEM for ever versus never exposed [HR 0.86 (95\% CI $0.41-1.82)$ and HR 1.18 (95\% CI 0.53-2.61), respectively].

For PhC, an elevated risk was observed for ever versus never exposed when using FINJEM [HR 2.20 (95\% CI 1.08-4.49)], but not when using DOMJEM [HR 1.16 (95\% CI 0.56-2.38)]. No trends of increased risks with higher cumulative exposure could be demonstrated when using DOMJEM or FINJEM. Certainly when using FINJEM, risk in tertile 3 of cumulative exposure was lower [HR $0.30(95 \%$ CI 0.04-2.46)] than in tertiles 1 and 2 [HR $4.04(95 \%$ CI 1.69-9.64)] and [HR 3.01 (95\% CI 1.14-7.96)].

For OCPC, results showed patterns similar to those observed for PhC, with tertiles 1 and/or 2 of the cumulative exposure showing an association [tertile 2 when using DOMJEM: HR 2.56 (95\% CI 1.28-5.09) and tertiles 1 and 2 when using FINJEM: HR 2.64 (95\% CI
1.34-5.19) and HR 2.15 (95\% CI 1.02-4.52), respectively]. The $\mathrm{P}$ for trend was non-significant for any of the cancer endpoints.

For ease of presentation, we will only present interaction results for FINJEM (table 3). Although the stratum-specific HR may be suggestive of a negative interaction between asbestos and smoking for OCC, none of the cancers showed a statistically significant interaction. Analyses with DOMJEM revealed no interactions (data not shown).

\section{Discussion}

This study showed no convincing evidence of an association between asbestos and risk of $\mathrm{OCC}, \mathrm{PhC}$, and $\mathrm{OCPC}$, as an exposure-response relation was lacking 
Table 3. Hazard ratios (HR) and 95\% confidence intervals (95\% Cl) for oral cavity and pharyngeal cancer both separately and combined, for asbestos exposure (yes/no) by smoking; estimated with a Finnish job-exposure matrix (FINJEM) in the Netherlands Cohort Study (NLCS), 1986-2003

\begin{tabular}{|c|c|c|c|c|c|c|c|c|c|c|c|c|c|}
\hline & \multicolumn{12}{|c|}{ Cigarette smoking } & \multirow{3}{*}{$\begin{array}{l}\text { P-value } \\
\text { for multi- } \\
\text { plicative } \\
\text { interaction }\end{array}$} \\
\hline & \multicolumn{4}{|c|}{ Never } & \multicolumn{4}{|c|}{ Former } & \multicolumn{4}{|c|}{ Current } & \\
\hline & $\begin{array}{l}\text { Person- } \\
\text { years }\end{array}$ & $\mathrm{N}$ & $\mathrm{HR}$ & $95 \% \mathrm{Cl}$ & $\begin{array}{c}\text { Person- } \\
\text { years }\end{array}$ & $\mathrm{N}$ & $\mathrm{HR}$ & $95 \% \mathrm{Cl}$ & $\begin{array}{l}\text { Person- } \\
\text { years }\end{array}$ & $\mathrm{N}$ & $\mathrm{HR}$ & $95 \% \mathrm{Cl}$ & \\
\hline \multicolumn{14}{|l|}{ Oral cavity cancer } \\
\hline Never exposed & 3124 & 7 & $1^{a}$ & .. & 10903 & 11 & 0.42 & $0.15-1.13$ & 6177 & 29 & 1.43 & $0.51-3.97$ & \\
\hline Ever exposed & 758 & 4 & 4.02 & $1.09-14.85$ & 3402 & 3 & 0.46 & $0.11-1.96$ & 2303 & 4 & 0.96 & $0.25-3.63$ & 0.13 \\
\hline \multicolumn{14}{|c|}{ Pharyngeal cancer } \\
\hline Never exposed & 3124 & 1 & $1^{a}$ & .. & 10903 & 13 & 3.45 & $0.44-27.00$ & 6177 & 22 & 5.14 & $0.60-44.13$ & \\
\hline Ever exposed & 758 & 1 & 7.81 & $0.49-123.45$ & 3402 & 3 & 3.06 & $0.30-30.90$ & 2303 & 13 & 16.37 & $1.92-139.38$ & 0.18 \\
\hline \multicolumn{14}{|c|}{$\begin{array}{l}\text { Oral cavity and } \\
\text { pharyngeal cancer } \\
\text { combined }\end{array}$} \\
\hline Never exposed & 3124 & 8 & $1^{a}$ & .. & 10903 & 24 & 0.81 & $0.35-1.88$ & 6177 & 53 & 1.88 & $0.78-4.54$ & \\
\hline Ever exposed & 758 & 5 & 4.60 & $1.40-15.04$ & 3402 & 6 & 0.79 & $0.26-2.43$ & 2303 & 17 & 3.05 & $1.18-7.92$ & 0.13 \\
\hline
\end{tabular}

${ }^{a}$ Adjusted for age (years), smoking status (never/former/current), number of cigarettes smoked per day (centered variable), years of smoking cigarettes (centered variable), level of education (three categories), alcohol consumption ( $\mathrm{g} / \mathrm{day})$, and consumption of vegetables (g/day).

and the ever versus never exposed estimates were inconsistent across both JEM. Nevertheless, some HR of PhC and OCPC were increased. Adjustment for especially alcohol consumption and socioeconomic status further increased HR of PhC and OCPC. Although the strataspecific HR may be suggestive of a negative interaction between asbestos and smoking for OCC, none of the cancers showed a significant interaction.

\section{Oral cavity cancer}

There are only few studies that have investigated the asbestos-related risk of OCC. These studies showed non-significantly increased risks $(20,21)$ as well as decreased risks $(22,23)$, with a recent meta-analysis revealing relative risk (RR) estimates of HR 1.13 (95\% CI 0.81-1.57) and HR 1.15 (95\% CI 0.84-1.57) for low and high exposure, respectively, based on five studies (3). Risk estimates in our study are in line with the results of the meta-analysis.

\section{Pharyngeal cancer}

For PhC, risk estimates of around one $(21,22)$ as well as increased risks have been reported after asbestos exposure in both overall $\mathrm{PhC}(23)$ and hypoPhC $(20,24)$. Our study reported multivariable-adjusted increased HR of $\mathrm{PhC}$ for ever versus never exposed to asbestos (HR 2.20, 95\% CI 1.08-4.49) when using FINJEM, but a trend of increased risks with higher cumulative exposure could not be demonstrated. Furthermore, given that results were not robust against the use of different JEM, one could conclude that our study showed no convincing evidence of an association between asbestos and $\mathrm{PhC}$. However, the number of cases in our study was small. A meta-analysis also showed increased risks of $\mathrm{PhC}$ without evidence of an exposure-response relation [relative risk (RR) of 1.26 (95\% CI 0.96-1.66) and 1.27 (95\% CI 0.98-1.66) for low and high exposure, respectively] (3), whereas a recent large case-control study observed an exposure-response relation (23). Therefore, the rather consistent observation of a possible association between asbestos and $\mathrm{PhC}$ could be more than a mere chance finding and warrants further research in studies with a larger number of cases.

\section{Oral cavity and pharyngeal cancer combined}

Because other studies mostly combined OCC and PhC, we also studied both cancers together (OCPC), notwithstanding the possibility that the asbestos-related risk may differ for both cancers. We found increased risks for ever versus never exposed and the $\mathrm{CE}$, similar to but less strong than for PhC. Results of previous cohort studies are rather consistent and show modestly increased risks with a meta-RR of 1.44 (95\% CI 1.04-2.00), while casecontrol studies are rather limited in number and show inconsistent results (5). Data on exposure-response patterns from both types of study are limited and tend towards lower risks for the more extreme exposures (5) as was the case in the present study. Another study using FINJEM found no exposure-response association either (4), but a meta-analysis stratifying results on exposure circumstance showed a RR of 1.63 (95\% CI 1.27-2.09) for asbestos miners and millers with the highest exposures (3). Due to the small number of cases, we were not able to run the analyses for the (prolonged) highly exposed subjects and test this result. Moreover, exposure levels of the miners and millers were probably much higher than in the NLCS.

Contrary to lung cancer, there is almost no epidemiological or experimental evidence addressing whether interaction may be present between asbestos and tobacco 
smoking in the development of OCC, PhC, and OCPC (5). Previous studies found no significant interaction for overall $\mathrm{PhC}$ (23) and hypoPhC (24). Our study also found no significant interaction for any of the cancers. The number of cases was small, however, and nondifferential asbestos exposure misclassification, due to using JEM, may have hampered finding significant results.

The present study suffers from some of the same limitations as previous studies, ie, a small number of cases and suboptimal characterization of asbestos exposure due to using JEM and the fact that information on occupational history was gathered at baseline in 1986 while study subjects were followed-up to December 2003. Nevertheless, our results are of importance for future meta-analyses given the limited number of studies on this subject. Moreover, the strengths of our study include the prospective design, the long, nearly complete follow-up, and the possibility to adjust for several lifestyle confounders. Evidence comes mainly from occupational cohorts that do often not allow for adjustment for potential confounders. Since HR of PhC and OCPC increased after adjustment for especially alcohol consumption and socioeconomic status, taking lifestyle factors into account may be important when studying these cancers. Furthermore, while our JEM-based exposure assessment possibly entailed non-differential exposure misclassification resulting most likely in bias towards the null value, a previous study in the NLCS using both DOMJEM and FINJEM was able to demonstrate the well-known associations between asbestos and cancers of the pleura and lungs (16). In addition, as study subjects were between 55-69 years of age at the start of the study in 1986, the amount of exposure misclassification resulting from the fact that we had no information on occupational history from 1986-2003 will probably be limited.

In conclusion, this study showed no convincing evidence of an association between asbestos and OCC, $\mathrm{PhC}$, and OCPC risk as an exposure-response relation was lacking and results were not robust against the use of different JEM. However, increased HR of PhC and OCPC were observed in this study as well as in previous studies and warrant further research.

\section{Acknowledgments}

The authors are indebted to the participants of this study and further wish to thank the Netherlands Cancer Registry and the Dutch Pathology Registry (PALGA). We also thank: S van de Crommert, Dr L Schouten, J Nelissen, C de Zwart, M Moll, S van den Heuvel, and A Pisters for their assistance with data-entry and/or data management;
L Preller for guidance regarding data-analyses with FINJEM; A Volovics and A Kester for statistical advice; and $\mathrm{H}$ van Montfort, $\mathrm{T}$ van Moergastel, E Dutman, and R Schmeitz for programing assistance.

The authors declare no conflicts of interest.

This study was supported by a grant from ZonMw (grant 50-50-500-98-6153). The sponsor had no role in the study design; collection, analysis, and interpretation of data; writing process; or decision where to submit the paper for publication.

\section{References}

1. Ferlay J, Shin HR, Bray F, Forman D, Mathers C, Parkin DM. Estimates of worldwide burden of cancer in 2008: GLOBOCAN 2008. Int J Cancer. 2010;127:2893-917. http:// dx.doi.org/10.1002/ijc. 25516 .

2. Schottenfeld D, Fraumeni J. Cancer Epidemiology and Prevention. New York: Oxford University Press; 2006. p. $627-37$.

3. Paget-Bailly S, Cyr D, Luce D. Occupational exposures to asbestos, polycyclic aromatic hydrocarbons and solvents, and cancers of the oral cavity and pharynx: a quantitative literature review. Int Arch Occup Environ Health. 2012;85:341-51. http://dx.doi.org/10.1007/s00420-011-0683-y.

4. Tarvainen L, Kyyronen P, Kauppinen T, Pukkala E. Cancer of the mouth and pharynx, occupation and exposure to chemical agents in Finland [in 1971-95]. Int J Cancer. 2008;123:653-9. http://dx.doi.org/10.1002/ijc.23286.

5. NAS. Asbestos: Selected Cancers: The National Academies, Institute of Medicine, Board on Population Health and Public Health Practices, Committee on Asbestos: Selected Health Effects. Washington, DC: The National Academies Press; 2006. p. 173-92.

6. International Agency for Research on Cancer (IARC). A Review of Human Carcinogens: Asbestos (Chrysotile, Amosite, Crocidolite, Tremolite, Actinolite and Anthophyllite). Lyon: IARC; 2012. IARC monographs on the evaluation of carcinogenic risks to humans, vol 100c.

7. van den Brandt PA, Goldbohm RA, van 't Veer P, Volovics A, Hermus RJ, Sturmans F. A large-scale prospective cohort study on diet and cancer in The Netherlands. J Clin Epidemiol. 1990;43:285-95. http://dx.doi.org/10.1016/08954356(90)90009-E.

8. Prentice RL. A case-cohort design for epidemiologic cohort studies and disease prevention trials. Biometrika. 1986;73:111. http://dx.doi.org/10.1093/biomet/73.1.1.

9. Casparie M, Tiebosch AT, Burger G, Blauwgeers H, van de Pol A, van Krieken JH, et al. Pathology databanking and biobanking in The Netherlands, a central role for PALGA, the nationwide histopathology and cytopathology data network and archive. Cell Oncol. 2007;29:19-24.

10. Van den Brandt PA, Schouten LJ, Goldbohm RA, Dorant E, 
Hunen PM. Development of a record linkage protocol for use in the Dutch Cancer Registry for Epidemiological Research. Int J Epidemiol. 1990;19:553-8. http://dx.doi.org/10.1093/ ije/19.3.553.

11. Goldbohm RA, van den Brandt PA, Dorant E. Estimation of the coverage of Dutch municipalities by cancer registries and PALGA based on hospital discharge data. Tijdschr Soc Gezonheidsz. 1994;72:80-4.

12. Hashibe M, Brennan P, Benhamou S, Castellsague X, Chen C, Curado MP, et al. Alcohol drinking in never users of tobacco, cigarette smoking in never drinkers, and the risk of head and neck cancer: pooled analysis in the International Head and Neck Cancer Epidemiology Consortium. J Natl Cancer Inst. 2007;99:777-89. http://dx.doi.org/10.1093/jnci/djk179.

13. Offermans NS, Vermeulen R, Burdorf A, Peters S, Goldbohm RA, Koeman T, et al. Comparison of expert and jobexposure matrix-based retrospective exposure assessment of occupational carcinogens in the Netherlands Cohort Study. Occup Environ Med. 2012;69:745-51. http://dx.doi. org/10.1136/oemed-2011-100556.

14. Peters S, Vermeulen R, Cassidy A, Mannetje A, van Tongeren $\mathrm{M}$, Boffetta $\mathrm{P}$, et al. Comparison of exposure assessment methods for occupational carcinogens in a multi-centre lung cancer case-control study. Occup Environ Med. 2011;68:14853. http://dx.doi.org/10.1136/oem.2010.055608.

15. Kauppinen T, Toikkanen J, Pukkala E. From cross-tabulations to multipurpose exposure information systems: a new jobexposure matrix. Am J Ind Med. 1998;33:409-17. http://dx.doi. org/10.1002/(SICI)1097-0274(199804)33:4<409::AIDAJIM12>3.0.CO;2-2.

16. Offermans NS, Vermeulen R, Burdorf A, Goldbohm RA, Kauppinen T, Kromhout H, et al. Occupational asbestos exposure and risk of pleural mesothelioma, lung cancer, and laryngeal cancer in the prospective Netherlands Cohort Study. J Occup Environ Med 2014;56:6-19. http://dx.doi. org/10.1097/JOM.0000000000000060.
17. Volovics A, van den Brandt PA. Methods for the analysis of case-cohort studies. Biometric J. 1997;39:195-214. http:// dx.doi.org/10.1002/bimj.4710390208.

18. Barlow WE, Ichikawa L, Rosner D, Izumi S. Analysis of casecohort designs. J Clin Epidemiol. 1999;52:1165-72. http:// dx.doi.org/10.1016/S0895-4356(99)00102-X.

19. Schoenfeld D. Partial residuals for the proportional hazards regression model. Biometrika. 1982;69:239-41. http://dx.doi. org/10.1093/biomet/69.1.239.

20. Reid A, Ambrosini G, de Klerk N, Fritschi L, Musk B. Aerodigestive and gastrointestinal tract cancers and exposure to crocidolite (blue asbestos): incidence and mortality among former crocidolite workers. Int J Cancer. 2004;111:757-61. http://dx.doi.org/10.1002/ijc.20313.

21. Purdue MP, Jarvholm B, Bergdahl IA, Hayes RB, Baris D. Occupational exposures and head and neck cancers among Swedish construction workers. Scand J Work Environ Health. 2006;32:270-5. http://dx.doi.org/10.5271/sjweh.1010.

22. Gustavsson P, Jakobsson R, Johansson H, Lewin F, Norel $\mathrm{S}$, Rutkvist LE. Occupational exposures and squamous cell carcinoma of the oral cavity, pharynx, larynx, and oesophagus: a case-control study in Sweden. Occup Environ Med. 1998;55:393-400. http://dx.doi.org/10.1136/oem.55.6.393.

23. Langevin SM, O'Sullivan MH, Valerio JL, Pawlita M, Applebaum KM, Eliot M, et al. Occupational asbestos exposure is associated with pharyngeal squamous cell carcinoma in men from the greater Boston area. Occup Environ Med. 2013;70:858-63. http://dx.doi.org/10.1136/ oemed-2013-101528.

24. Marchand JL, Luce D, Leclerc A, Goldberg P, Orlowski E, Bugel I, et al. Laryngeal and hypopharyngeal cancer and occupational exposure to asbestos and man-made vitreous fibers: results of a case-control study. Am J Ind Med. 2000;37:581-9. http://dx.doi.org/10.1002/(SICI)10970274(200006)37:6<581::AID-AJIM2>3.0.CO;2-D.

Received for publication: 26 November 2013 